\title{
SENTIDOS DE ENSINO DE MÚSICA NAS NARRATIVAS DE DOCENTES DOS ANOS INICIAIS
}

\section{SENSE OF MUSIC EDUCATION IN THE NARRATIVES OF TEACHERS OF BASIC EDUCATION}

DOI: http://dx.doi.org/10.5965/1984317816012020330

Isamar Marques Cândido Pales

Universidade Estadual do Sudoeste da Bahia isamarmcp@hotmail.com

Sandra Suely Oliveira Souza

Universidade Estadual do Sudoeste da Bahia sandraso.s@hotmail.com

Sandra Márcia Campos Pereira Universidade Estadual do Sudoeste da Bahia sandra.campos@uesb.edu.br

\author{
Benedito Eugenio \\ Universidade Estadual do Sudoeste da Bahia \\ dodoeugenio@gmail.com
}

\begin{abstract}
RESUMO
A música está presente em nosso cotidiano e desperta os mais diferentes sentimentos. Neste artigo, apresentamos os resultados de uma pesquisa que objetivou compreender as configurações subjetivas acerca da relação entre música e prática docente. Os dados apresentados neste artigo fazem parte de uma pesquisa sobre sentidos de música para pedagogas que atuam na docência dos anos iniciais do ensino fundamental no município de Vitória da Conquista-Ba. Empregamos a entrevista narrativa para a produção dos dados e a fenomenologia é o método de análise. Os dados foram organizados em categorias. Neste texto apresentamos duas dessas categorias: o ressoar da música no curso de Pedagogia; Configurações de sentido da música para as pedagogas. As conclusões apontam que o momento das narrativas oportunizou cada participante trazer o relato sobre a compreensão da música. O acesso ao material nos revelou vivências aproximadas e outras mais distantes no que tange à representatividade e ao sentido da música.
\end{abstract}

Palavras-chave: Ensino de música. Narrativas. Fenomenologia.

\begin{abstract}
Music is present in our daily lives and awakens the most different feelings. In this article, we present the results of a research that aimed to understand the subjective configurations about the relationship between music and teaching practice. The data presented in this article are part of a research on the meanings of music for pedagogues who teach in the initial years of elementary education in the city of Vitória da Conquista-Ba. We use the narrative interview for the production of data and phenomenology is the method of analysis. The data were organized into categories. In this text we present two of these categories: the resounding of music in the Pedagogy course; music configurations for pedagogues. The conclusions point out that the moment of the narratives allowed each participant to bring the story about the understanding of music. The access to the material revealed us approximate experiences and others more distant with respect to the representativeness and the meaning of the music.
\end{abstract}

Keywords: Teaching music. Narratives. Phenomenology 


\section{INTRODUÇÃO}

A música é uma linguagem presente em nosso cotidiano, exercendo papel essencial na sociedade e proporcionando abertura de caminhos para a vivência de diversas emoções e sentimentos, seja por meio da palavra ou apenas pela melodia. Ela soa em diferentes contextos, tais como: no trânsito, no trabalho, nas igrejas, nas clínicas, nos estádios, no cinema, nas cerimônias oficiais, nas escolas, etc.

A música nos remete a experiências vividas promovendo repensar e reviver o mesmo ser. O reconhecimento acerca da importância da música na escola engloba pontos cruciais da vivência humana, tendo em vista que a música oportuniza experiências singulares e também promove o aprendizado.

Neste artigo, buscamos compreender as configurações subjetivas acerca da relação entre música e prática docente. Esse movimento foi possível por meio das narrativas do mundo percebido de docentes dos anos iniciais do ensino fundamental frente ao fenômeno musical.

\section{METODOLOGIA}

Os dados apresentados neste artigo fazem parte de uma pesquisa sobre sentidos de música para pedagogas que atuam na docência dos anos iniciais do ensino fundamental no município de Vitória da Conquista-Ba. A pesquisa foi submetida e aprovada pelo Comitê de Ética em Pesquisa da UESB sob o número CAAE 84467317.3.0000.0055.

As participantes da pesquisa foram pedagogas egressas da UESB, formadas entre os anos de 2015 a 2017 e docentes dos anos iniciais do ensino fundamental. Os dados foram construídos por meio de entrevistas. Após a etapa detalhada de escuta e transcrição das falas, chegamos ao momento da interpretação.

Apresentamos uma questão desencadeadora a fim de provocar e ter acesso às impressões das pedagogas acerca do curso formativo. Tal prerrogativa não tem o 
objetivo de adentrar numa discussão sobre o currículo, mas oferece a oportunidade do pedagogo externar sua impressão sobre os conhecimentos construídos na formação para a sua prática pedagógica, como também possibilita refletir e abordar as possíveis lacunas em relação à vivência com a música durante o percurso de formação das participantes.

As análises tomaram como base as contribuições da fenomenologia. Consideramos que ao investigar a história de atuação profissional das participantes estamos adentrando na forma como elas constroem a vida cotidianamente ansiando perceber o fenômeno. Bicudo (1994, p.18) complementa que, de tal forma, "o que é percebido, nunca é visto sem que seja olhado. É o invisível se mostrando, tornandose visível. Para tanto, solicita um ver e uma consciência atenta que o veja".

Quanto à natureza do fenômeno pesquisado, pontuamos que não pode ser compreendido como verdade última e absolutamente dada. Acontece um movimento correlato de perceber que a verdade é subjetiva e relativa. Bicudo (1994) esclarece que tal processo envolve o ser-no-mundo, visto que, "perceber o fenômeno quer dizer que há um correlato e que a percepção não ocorre no vazio, mas em um estarcom-o-percebido" (BICUDO, 1994, p. 19). Esse caminho permite nascer o ser reflexivo e questionador que se impõe diante das situações vividas individual e socialmente.

Desse modo, adentramos no mundo sensitivo e perceptivo das participantes objetivando a interpretação significativa do sentido referente à música. Consideramos que o caminho traçado envolve interligações entre vivências, práticas, percepções, julgamentos e hipóteses. É significativo destacar que nossas vivências com o fenômeno musical traçadas em uma experiência a priori, foram dispositivos contribuintes reflexivos para a interpretação das narrativas. Podemos dizer que a percepção que temos da música será um processo de co-percepção, no sentido atribuído por Bicudo (1994, p.20): "co-participação dos sujeitos em experiências vividas permite partilhar, compreensões, interpretações, comunicações, conflitos, estabelecendo-se a esfera da intersubjetividade".

Um campo de percepção é construído envolvendo os co-percebidos e o fenômeno em questão. Nas palavras de Bicudo (1994, p. 18), "sujeito e fenômeno 
são no mundo-vida juntos com outros sujeitos, co-presenças que percebem os fenômenos". Esse movimento exige duas vias de interpretação a facilitada e a dificultada. A primeira, porque a linguagem oportuniza a compreensão por meio da fala e da escrita. Por outro lado, se torna dificultada, no que tange à incapacidade de compreensão total do vivido, ou seja, as palavras e os signos não são capazes de interpretar totalmente o que é vivenciado. Nesse sentido, Bicudo (1994, p. 19) esclarece que "as palavras não dizem tudo e não são objetivamente dadas, ou seja, não há uma relação biunívoca entre palavra e experiência vivida. Portanto, o comunicado solicita uma hermenêutica, isto é, clama por uma interpretação de sentidos e dos significados que pode expressar".

Merleau-Ponty também declara:

Em suma, toda linguagem se ensina por si mesma e introduz seu sentido no espírito do ouvinte. Uma música ou uma pintura que primeiramente não é compreendida, se verdadeiramente diz algo, termina por criar por si mesma seu público, quer dizer, por secretar ela mesma sua significação (MERLEAU-PONTY, 1999, p. 244).

Ao tecermos tais considerações e chegando a esse ponto, vamos encontrar falas muito profícuas que nos permitem emergir em torno das notas afinadas, desafinadas, melodiosas, ritmadas ou descompassadas, compondo a melodia do nosso texto. Escolhemos os nomes, seguindo a ordem das entrevistas realizadas, quais sejam: Sonata, Acappela, Sonatina, Melisma e Melodia. As pedagogas participantes tiveram a oportunidade de relatar fatos de sua vida inicial acadêmica e profissional, permitindo o desvelar de suas impressões e expectativas acerca de motivações e escolhas quanto ao processo formativo, à carreira docente e às práticas desenvolvidas nos anos iniciais do ensino fundamental.

Na sequência, apresentamos os dados construídos por meio das entrevistas realizadas com as pedagogas, ou seja, o caminho de ressonância das narrativas. 


\section{RESULTADOS E DISCUSSÃO}

\section{O ressoar da música no curso de pedagogia}

Interessou-nos conhecer até que ponto a música teve espaço no curso de Pedagogia. Assim, lançamos a pergunta ansiando ouvir os relatos narrativos no que tange às vivências musicais oportunizadas no decorrer do processo formativo.

As respostas demonstraram os indicativos de descontentamento acerca da ausência da música no processo formativo. As participantes relataram sentir uma grande lacuna referente às discussões, atividades e formas de trabalhar a música na sala de aula. Sonata e Melisma afirmaram não ter recordação de algum momento educativo com música.

No curso eu não me lembro de ter essa vertente mais artística e musical (SONATA, 2018).

[...] a gente aprendia aquelas coisas pra trabalhar com a educação infantil, mas o momento assim que eu me lembre que teve esse processo direto de trabalhar a música, não (MELISMA, 2018).

Percebemos que as atividades musicais oferecidas no curso são de cunho psicomotor, buscando trabalhar a coordenação e a expressão corporal. Existe uma simplificação da unidocência nos anos iniciais e a questão se amplia quando pensamos na educação musical, no que é desenvolvido como prática musical.

Ainda interpretando a fala de Melisma, a associação da música com "aquelas coisas", vemos que tal expressão denota a fragilidade do trabalho desenvolvido, visto que, não elencou indicadores significativos para a sua prática pedagógica. Percebemos que o aspecto ganha proporção quando ela menciona a ausência do processo direto com a música; isso representa que, da forma como foi apresentado no curso não houve configuração de sentido como musicalização ou envolvimento musical simbólico. Brito (2011, p.55) destaca que:

A primeira e mais importante questão diz respeito à necessidade de reformulação dos programas de ensino dos cursos de formação de profissionais para o ensino de música, que devem desenvolver uma visão global e integradora do mundo, abordando o conhecimento de 
uma maneira abrangente, contextualizada e relacional, atualizando conceitos e conteúdos musicais que devem incluir a estética da música contemporânea e das músicas não ocidentais, só para relembrar alguns pontos.

França (2016, p.89) demonstra sua inquietação acerca da urgência em busca do reconhecimento da música como área e da educação musical como disciplina. Nesse sentido, declara que "é na afirmação da especificidade da nossa área que podemos revelar sua multidimensionalidade". Percebemos que da maneira como é apresentada no curso de Pedagogia, a música não recebe o devido valor e não ocupa nenhum dos lugares, ou seja, não é vista como área, nem como disciplina.

Sonatina e Melisma trouxeram seus relatos acerca do pequeno ou ausente espaço dado à linguagem musical, reforçando o discurso recorrente sobre a continuidade de discussões e estudos conteudistas, como também acerca da carência dessa arte nos espaços formativos. Assim relataram:

A gente vê tão pouco, principalmente na universidade isso não é muito trabalhado não. É mais conteúdo, trabalho, e todo mundo correndo, vários seminários e tal. Acho que a gente deveria ter disciplinas disso, porque querendo ou não, nós como pedagogos, a gente tem que trabalhar isso, a gente tem que trabalhar. Quando se fala em psicomotricidade a gente pode utilizar tudo isso (SONATINA, 2018).

Porque a aula de artes sai daquele negócio da leitura, então eu acho que isso seria maravilhoso no curso de Pedagogia. Porque por exemplo, eu não sou uma pessoa criativa, então se a gente pudesse aprender formas mais criativas dentro do nosso curso de Pedagogia pra trabalhar com nossos alunos, isso seria tão enriquecedor pra gente, seria maravilhoso (MELISMA, 2018).

Esse é o quadro perceptivo figurado pelas entrevistadas. Um curso que não prioriza as linguagens artísticas, porque a valorização é destinada às disciplinas conteudistas, às avaliações, leituras de textos, seminários incontáveis, dentre outras atividades presentes no currículo. Não estamos desmerecendo o espaço dos conhecimentos objetivos, contudo, pensamos que dentro do currículo podem existir 
componentes destinados a trabalhar a música, a dança, o teatro, ou seja, as expressões artísticas.

Bellochio (2014, p.51) afirma que "pensar na formação musical na Pedagogia requer mirar a complexidade do processo formativo que, por natureza é de ordem da teoria e da prática. A música possui uma vertente teórica e prática que pode ser distribuída de forma a atender os interesses das pedagogas que irão atuar na sala de aula.

Acerca da música no processo formativo, Sonatina narrou presenciar momentos escassos em uma disciplina. Esse período marcava o final da aula com a exibição de um clipe musical, ou audição de uma música, promovendo reflexões, relaxamento e resgate de memórias. E comenta:

[...] era um momento muito interessante, dava pra gente relaxar depois da aula, curtir um pouco a música, e a gente saia até um pouco mais aliviado do dia tão cansativo, de uma noite tão exaustiva Eu (SONATINA, 2018).

Como bem define Fischer (1987), dentre todas as artes, a única que ativa sensações elevadas nos seres humanos é a música. Contudo, pensamos que sua presença na educação não atende apenas esse fim. É recorrente relacionar a música ao relaxamento.

As reflexões e provocações de Penna (2014) são relevantes e nos impulsionam repensar o que está sendo desenvolvido como práticas musicais dentro das escolas e dos espaços de formação de professores. Segundo a autora, os docentes não possuem formação específica e acabam apresentando a música de maneira superficial e descontinuada.

Consideramos que o contato com a música é um dispositivo que abarca aspectos amplos e múltiplos. De acordo com a narrativa da entrevistada, foi apresentado um tipo de vivência musical durante o percurso acadêmico, e somente uma disciplina abriu espaço para a expressão artística musical. Nesse sentido, consideramos que grandes lacunas no que tange ao contato com a música ficam à deriva. 
Em contrapartida, destacamos o relato de Melodia e as considerações relevantes acerca da presença da música no curso de Pedagogia. A pedagoga foi a única participante que teve a oportunidade de participar de momentos musicais substanciais para a sua formação e prática pedagógica. Enfatiza o papel da professora que ministrou a disciplina de Estágio na Educação Infantil:

[...] ela mostrou pra gente o olhar critico sobre a música que você leva pra criança. Como é que eu penso em uma música pra criança, como eu seleciono uma música pra levar pra sala de aula. Enxergar para além do que tem no mercado, não é só isso aqui, eu tenho que oferecer variedade, eu tenho que oferecer para além das músicas infantis. Então todo esse olhar, a professora trouxe e foi despertado (MELODIA, 2018).

Sua narrativa traduz aspectos significativos para o trabalho de percepção e apreciação. O ato de conscientização e sensibilização acerca da música configurase como um dos pilares para o início da educação musical.

O aprendizado da música envolve a constituição do sujeito musical, a partir da constituição da linguagem da música. O uso dessa linguagem irá transformar esse sujeito, tanto no que se refere a seus modos de perceber, suas formas de ação e pensamento, quanto em seus aspectos subjetivos. Em consequência, transformará também o mundo deste sujeito, que adquirirá novos sentidos e significados, modificando também a própria linguagem musical (FONTERRADA, 1994, p. 41).

Houve o despertar, por parte de Melodia, do entendimento e o processo foi construído a cada dia, e enfaticamente depois da vivência na disciplina de Estágio na Educação Infantil. Suas palavras denotam a singularidade da proposta desenvolvida pela professora da referida disciplina.

[...] acho que o momento mais forte foi esse, que ela ensinou pra gente a ter o olhar crítico e a mostrar que, não é porque o trabalho com música é na educação infantil, que eu tenho que levar só Dona aranha, O sapo não lava o pé ou só as músicas infantis. Eles também tem que ter contato com a música clássica, com MPB, com o rock, com todos os outros estilos para que eles conheçam e para que o ouvir deles também vá se abrir como um leque (MELODIA, 2018). 
Melodia menciona a criticidade da professora da disciplina em ampliar o repertório dos alunos, não apresentando e cantando somente cantigas do contexto infantil e folclórico. Tal aspecto despertou a nossa co-percepção para desvelar leituras interpretativas. Não estamos desmerecendo o espaço das cantigas, que consideramos de suma importância no processo de musicalização. Porém, mencionamos a recorrência da exiquidade do trabalho musical desenvolvido enfatizando somente as cantigas infantis. Falamos em mediania considerando o termo como algo que é feito dentro da média, da região de conforto dos professores. Desse modo, consideramos o estar-professor como um processo de constante aprendizado e conhecimento, ou seja, "não nascemos professores, nos tornamos professores diariamente" (DALLABRIDA, 2015, p. 64).

A narrativa de Melodia nos revelou sua percepção acerca da intensidade do valor dado à expressão musical por meio de vivências em uma disciplina. Conforme o relato da participante, as discussões realizadas serviram de inspiração para ampliar o repertório musical, bem como, as atividades musicais a serem desenvolvidas. Não tivemos a informação sobre a formação da docente que ministrou a disciplina. Contudo, tecemos a importância do momento no curso de Pedagogia, visto que oportunizou um contato, mesmo breve, com a linguagem musical de forma expressiva e consciente.

Partimos do pressuposto de que o processo se fortaleceu para Melodia devido ao seu envolvimento prévio com a arte, ou seja, ela já dispunha de conhecimento e sensibilidade acerca da música e de seu valor para a educação. $\mathrm{O}$ processo formativo não foi o nascedouro para sua sensibilidade acerca da arte, mas suas experiências e vivências prévias ao curso.

Um ponto externado na fala da entrevistada que merece uma leitura, referese à ênfase recorrente à presença da linguagem musical na educação infantil. Em sua narrativa, a professora não menciona atividades musicais direcionadas aos primeiros anos do ensino fundamental, que é o foco do nosso estudo. Mais uma vez, reforçamos a urgência em desmitificar a ideia de que a música na escola é restrição ou privilégio das crianças pequenas. 
Enxergamos tal conjuntura de valorização da linguagem musical mais recorrente na educação infantil, ao interpretar a narrativa de Acappella. Sua narrativa sobre a música no curso demonstra que esta se fez presente na disciplina que trata dessa etapa da educação básica. Assim ela diz:

A gente teve só uma disciplina que eu enxerguei isso de perto, que foi na de Educação Infantil. A professora levou música, colocou a gente pra ir pra roda. Essa prática a gente só viu nessa disciplina. Eu vi o quanto é importante, porque assim todos participam, todos se envolvem nesse processo. Você se sente participante da aula. Nessa disciplina, teve uma semana que a professora levou a gente pra uma sala diferente. Tinha uns espelhos, um tatame no chão e a gente voltou a ser criança (ACAPPELLA, 2018).

Mais uma vez, a narrativa expõe a presença solitária da música. Diante de tantos componentes e de conteúdos apresentados no processo formativo, a arte ocupou um singelo lugar de audição e cantigas de roda. Tal assertiva reforça nossa inquietação e busca pela visibilidade do encantamento da música. Apesar disso, a entrevistada complementa o valor que teve esse momento. Sua fala traduz aspectos relevantes de envolvimento, socialização e resgate de momentos vividos. Consideramos que experiências como a descrita acima precisam ser mais frequentes no processo de formação docente. Percebemos nas palavras de Acappella que houve um significado expressivo para sua vida. No decorrer da narrativa, foi perceptível o olhar radiante de Acappella ao relatar o que foi vivenciado nesse dia.

Tal conjuntura nos leva a compreender que voltar a ser criança, é retornar às práticas divertidas e cheias de alegria. A música desperta emoções diversas e dentre tantas, o sentimento de alegria, de festa, de brincadeira. Esse aspecto é abordado por Snyders (2008) e ele declara que na perspectiva de sociedade atual, tais momentos de alegria, mesmo escassos e não sequenciais são estimulantes para a vida difícil e por vezes árdua dos seres humanos.

O referido autor trata das alegrias que a escola pode proporcionar ressaltando o espaço não somente como lugar para a formação de pessoas para o futuro, como também para a vida adulta, para o trabalho e para as vivências em frente à realidade. Assim, o autor complementa: "Propiciar uma alegria que seja 
vivida no presente é a dimensão essencial da pedagogia, e é preciso que os esforços dos alunos sejam estimulados, compensados e recompensados por uma alegria que possa ser vivida no momento presente" (SNYDERS, 2008, p. 18).

O mundo precisa de alegria, de viver estágios de expressão e expansão, porém, tais vivências não precisam ser exclusas do ambiente educativo. $O$ autor supracitado externa sua inquietação enquanto pedagogo, em perceber que as alegrias são vivenciadas somente nos espaços extra-escolares, considerando a escola "simplesmente como o local onde devem desincumbir-se de uma certa quantidade de tarefas prescritas" (SNYDERS, 2008, p. 18).

Os relatos das pedagogas evidenciam que o curso de Pedagogia pouco valoriza o espaço de vivências alegres. No que concerne aos momentos musicais, esses são opacizados e esporádicos, não representando a real valorização das alegrias que a música pode proporcionar. Recorremos mais uma vez às palavras de Snyders, concordando com a multiplicidade do fazer musical e sua capacidade de "despertar emoções controladas, que integrem a alegria ao conjunto da pessoa, tanto na sua sensibilidade quanto na sua compreensão" (SNYDERS, 2008, p. 30).

As inquietações e provocações acerca da inserção da música no processo formativo permeiam nosso caminho em um movimento constante. Mesmo sendo um discurso por vezes solitário, não podemos deixar que permaneça na indiferença a importância das vivências e práticas musicais no curso de Pedagogia. Nesse sentido, vale destacar as considerações da autora Hentschke (2003), quando declara que o sistema educacional sempre deu ênfase e reconhecimento às disciplinas enquadradas como "centrais" e consideradas como essenciais para a formação dos sujeitos. A autora apresenta a sua provocação quando externa suas reflexões instigantes.

É pouco provável encontramos professores de matemática ou ciências lutando pelo reconhecimento externo sobre a importância de suas disciplinas. Dificilmente presenciamos reuniões ou identificamos pautas de reuniões, ou espaços reservados para a discussão de uma filosofia comum baseada na natureza da matemática ou das ciências (HENTSCHKE, 2003, p. 56). 
Realmente, não temos conhecimento de luta de professores de Português, História ou Geografia pela visibilidade de suas disciplinas. Porém, a busca pelo reconhecimento da educação musical já perdura por alguns anos e parece que estar sempre a ocupar um lugar menos importante. Falamos disso, relembrando as leis 11.769/2008 e 13.279/2016, já tratadas nesse trabalho, que trazem a música para o campo obrigatório da escola. Nessa linha, o autor Marcos Ferreira declara que "fosse o ensino de música recorrente em todas as escolas, não se fazia necessária a implementação de uma lei específica para sua inserção nas escolas" (FERREIRA, 2017, p. 52). Realçamos que temos duas leis e não vemos o processo concretizado. Portanto, o que é percebido acerca da efetivação da música no âmbito educativo revela um problema recorrente em cidades da Bahia e do Brasil.

Tal constatação também nos representa, quando percebemos que a busca envolve outros aspectos de ordem maior. A música ocupa um parco espaço dentro da disciplina de Artes nas escolas regulares, e nos cursos de formação é praticamente ausente sua representação. Rememoramos a Resolução $n^{\circ} 2$, de 10 de maio de 2016, que estabelece a inserção do ensino de música nos currículos dos cursos de Pedagogia. Consideramos que não bastam leis, resoluções ou diretrizes, se as instituições não promovem ações transformadoras em prol da música. Diversas pesquisas quantitativas foram realizadas e o percentual da presença da música nos cursos de Pedagogia é baixo. Um desses estudos da autora Dallabrida constatou que é praticamente inexistente o conteúdo musical na formação acadêmico-profissional do professor unidocente. Consequentemente, o resultado é o fazer repetitivo das atividades de artes visuais, como realça a autora.

A configuração das Artes deveria englobar Artes Visuais, Teatro, Dança e Música, contudo, na maioria das universidades, todas estas correspondem a uma disciplina, ministrada por um único professor. Este, na maioria das Instituições, é habilitado em Artes Visuais, o que torna esta linguagem predominante em relação às demais. (DALLABRIDA, 2013, p.36-37)

Conforme foi citado nesse trabalho, o curso de Pedagogia da UESB não oferece educação musical. Em contrapartida, percebemos o interesse das pedagogas, por meio dos discursos em favor da música. Os relatos das 
entrevistadas denotam que a consideram um indicador importante para a formação, para a vida e para a educação. Contudo, persiste a dissociação entre o falar e o fazer. Percebemos que ainda em grande maioria, os modelos que formam professores não promovem saberes necessários para atender à realidade dos seus cotidianos. Compreendemos que o fazer musical revela-se desarticulado por que os profissionais atuantes não obtiveram a mínima formação acerca da linguagem musical.

Percebemos que por um lado a música é reconhecida no discurso, porém, continua fora do processo formativo. Esse ponto revela que o problema é maior e requer amplas movimentações envolvendo a conscientização de mais pessoas. Como declara a mesma autora "julgo necessário que seu conteúdo pedagógicotécnico seja trazido ao entendimento dos pais, dos professores de outras áreas, bem como, e principalmente, dos alunos a quem a educação está direcionada" (HENTSCHKE, 2003, p. 55).

Além de desvelar e compreender as impressões sobre as vivências com a música dentro do curso de Pedagogia, é nosso interesse conhecer o sentido que as pedagogas atribuem à música. Portanto, seguimos na direção de interpretação acerca da linguagem musical na vida das entrevistadas.

Configurações de sentido da música para as pedagogas: por uma linguagem simbólica e fenomenológica

A palavra sentido refere-se ao que é muito pessoal e íntimo da compreensão humana, está ligado à subjetividade. Nesses termos, existe uma diferença entre o que é vivido socialmente e o sentido que essa vivência tem para o sujeito (REY, 2011). O autor aprofunda mais ainda acrescentando o termo subjetivo, compondo o sentido subjetivo, que é tratado como o dispositivo processual do que existe de simbólico e emocional em toda a vivência humana (REY, 2002).

Tomando como base o termo de sentido subjetivo de Rey (2011), ansiamos compreender e interpretar quais as configurações de sentido da música na prática das pedagogas. Tal movimento envolve um retroceder ao vivido, voltar-as-coisas- 
mesmas ou ir à experiência compartilhada, estabelecendo um diálogo de intersubjetividade. De acordo com este autor:

Toda experiência humana tem infinitas questões a ser percebidas, refletidas e memorizadas, porém, só percebemos, refletimos e memorizamos aqueles aspectos que ganham sentido subjetivo dentro da configuração subjetiva que emerge no curso da experiência vivida que representa o momento vivido da personalidade na ação do sujeito (REY, 2011, p. 35).

É importante destacar que tal configuração subjetiva não representa um fato isolado do vivido do sujeito. Ela assume uma função de organizar o sistema individual subjetivo em desenvolvimento, ou seja, é a personalidade no instante da atividade. Nas palavras do mesmo autor, "o núcleo que dá cor às experiências vividas é a configuração subjetiva dessa experiência, na qual aparece a relação inseparável e em movimento da personalidade e do contexto" (REY, 2011, p.35).

Merleau-Ponty traça abordagens acerca da relação entre linguagem e pensamento, esclarecendo que "pensar é, com efeito, uma experiência, no sentido em que nós damos nosso pensamento pela fala interior ou exterior" (MERLEAUPONTY, 1999, p. 241). A fala foi o caminho para a exteriorização, ou seja, o desvelar do que pensam as pedagogas sobre a música.

Consideramos a relação entre linguagem e pensamento como o caminho diretivo para compreender o sentido dado ao fenômeno musical. Nessa conjuntura, a palavra reforça o pensamento que já está dotado de significação. Recorrendo ao mesmo autor, percebemos que "a fala e o pensamento só admitiriam essa relação exterior se um e outro fossem tematicamente dados; na realidade, eles estão envolvidos um no outro, o sentido está enraizado na fala, e a fala é a existência exterior do sentido" (MERLEAU-PONTY, 1999, p. 247).

As narrativas das pedagogas foram utilizadas para o caminho de desvelamento do sentido da música, visto que fornecem indicadores por meio da ação humana atuando como responsáveis pela conotação de subjetividade. Toda ação sugere uma produção singular de algo simbólico-emocional envolvendo o corpo e os espaços em que atua. A configuração subjetiva é o resultado das 
impressões, das hipóteses inter-relacionadas que emergidas ganham sentido no decorrer da experiência vivida. Concordamos que:

Ela é sempre a organização atual que o sistema subjetivo individual assume em seu desenvolvimento, ela é a personalidade no momento atual da ação. É este o aspecto central da definição do subjetivo; o núcleo relevante que dá cor às experiências vividas é a configuração subjetiva dessa experiência, na qual aparece a relação inseparável e em movimento da personalidade e do contexto; a configuração subjetiva é a produção subjetiva em que essa unidade em movimento aparece em cada momento da experiência da pessoa (REY, 2011, p. 35)

Neste estudo, o contexto é a sala de aula, e as experiências são definidas pelas práticas musicais das professoras. Consideramos cada momento como único e gerador de sentidos e subjetividades. Portanto, torna-se oportuno compreender as configurações do sentido da música nas ações vividas pelas professoras em seus contextos pessoais, educacionais e profissionais.

Outro aspecto a ser destacado é o caráter não racional da configuração de sentido subjetivo. Mesmo que esse processo envolva reflexões e representações, consideramos que somente esses dispositivos não resolvem o caminho da compreensão da subjetividade. Segundo Rey (2011, p.36) "novos caminhos que se abrem vão implicar novas configurações subjetivas cujo curso vai estar além desses processos". Assim, esse estudo não apresenta um fim definido, mas oportuniza outras leituras, outras notas e outros tons de melodias e interpretações. Nesse sentido, persiste nosso interesse em conhecer as experiências musicais vivenciadas pelas pedagogas oriundas da UESB, buscando desvelar os sentidos e as subjetividades originadas das ações e interpretações destas atividades.

Desse modo, o momento das narrativas oportunizou cada participante trazer o relato sobre a compreensão da música. O acesso ao material nos revelou vivências aproximadas e outras mais distantes no que tange à representatividade e o sentido da música. Ao lançarmos a pergunta sobre o sentido da linguagem musical, as participantes se deixaram mergulhar nas percepções musicais. Sonata externou escutar, sentir e amar música. Já Melisma e Acappela demonstraram a compreensão acerca da música por meio do âmbito social educativo. 
[...] essencial na vida das pessoas, qualquer pessoa que você perguntar você gosta? Claro! Todo mundo gosta. Existem diferentes tipos de música, diferentes interesses com a música, mas enfim, todas as pessoas gostam (SONATA, 2018).

Eu acho que a música ela tem um poder tão grande, não só na sala de aula, mas em todos os sentidos. Eu acho difícil a gente viver sem música, eu mesmo adoro ouvir música, e na sala de aula é de extrema importância (MELISMA, 2018).

Eu acho que através da música a gente consegue se conectar com o outro. Essa questão da sensibilidade, de você conseguir enxergar o que o outro está sentindo, de você mostrar pro outro que você se importa, que você está ali (ACAPPELA, 2018).

As falas traduzem a subjetividade marcante nos discursos velados de sentimentos. A música tem um poder, estabelece conexões e torna-se essencial na vida dos seres humanos, configurando-se com uma linguagem presente por meio de experiências vividas. Chegar a interpretar o fenômeno não é tecido como algo fácil, pois envolve cenários sociais diversos. Para tanto, pensamos em consonância com as palavras do autor:

A ênfase nas configurações subjetivas como recurso de conhecimento sobre as experiências de vida da pessoa implica conhecer a importância do trabalho de campo nos cenários sociais das pessoas estudadas, o que permitirá uma compreensão mais rica e profunda da forma como essas pessoas desenvolvem e compreendem a música (REY, 2011, p. 38, grifos nossos).

É inebriante a narrativa em torno da música. Torna-se algo de fácil aceitação, pois desconhecemos seres humanos alheios ao contato musical, visto que tal arte rodeia nosso corpo e nosso mundo, trazendo o dito popular de que somos um povo muito musical. Levitin afirma que "a música diferencia-se de todas as outras atividades humanas por sua simultânea ubiquidade e antiguidade" (2010, p. 12). Tal declaração é assertiva, pois não temos conhecimento de nenhuma civilização humana contemporânea ou de outra época que tenha a música como algo inexplorado ou desconhecido. Todos os seres humanos, de alguma maneira, fazem, vivem e estão em contato com a linguagem musical. Nas palavras de Merleau-Ponty "a música, inversamente, está muito aquém do mundo e do 
designável para figurar outra coisa senão épuras do Ser, seu fluxo e seu refluxo, seu crescimento, suas explosões, seus turbilhões" (MERLEAU-PONTY, 2004, p. 12).

Externar sobre a música não é visto como algo difícil para alguns. Percebemos que as participantes não demonstraram estranheza ou restrição em falar sobre o que pensam acerca da música. Mesmo tecendo discursos nivelados quanto ao aporte musical, cada uma declarou sua aproximação e visão sobre o fenômeno musical. Conforme Beyer e Kebah (2016), cada pessoa pode interpretar e dar significados sobre o universo musical independente do conhecimento e aprofundamento teórico. Merleau-Ponty afirma que "a fala é um verdadeiro gesto e contém seu sentido, assim como o gesto contém o seu. É isso que torna possível a comunicação. Para que eu compreenda as falas do outro, evidentemente é preciso que seu vocabulário e sua sintaxe "já sejam conhecidos" por mim" (MERLEAUPONTY, 1999, p. 249).

Cada sujeito fala de sua relação com o fenômeno musical de maneira peculiar, e todas as entrevistadas revelaram a proximidade com a música. Conforme foi tratado anteriormente, a linguagem musical exerce uma função primordial na vida dos seres humanos marcando presença desde os primórdios tempos da civilização. As palavras do autor refletem que os sujeitos desenvolvem um diálogo com o objeto próximo, que nesse estudo, é direcionado à música.

Esse diálogo do sujeito com o objeto, essa retomada pelo sujeito do sentido esparso no objeto e pelo objeto das intenções do sujeito que é a percepção fisionômica, dispõe em torno do sujeito um mundo que Ihe fala de si mesmo e instala no mundo seus próprios pensamentos (MERLEAU-PONTY, 1999, p. 185).

As narrativas apresentam aspectos singulares característicos de cada sujeito e tal caminho foi revelando minúcias das pedagogas. A fala de Sonatina demonstra sua expansividade ao falar do sentido da música. Envolve ouvido, corpo, emoção, por isso, relatou não ter uma definição direta justificada diante da abrangência emocional e corporal vivenciada pelo contato musical. $\mathrm{Na}$ mesma itinerância segue a fala de Melodia. Eis as narrativas:

Música para mim não tem algo definido. A gente sabe que é aquilo que a gente ouve, que é bom, é aquilo que me toca, que emociona, 
que me traga alguma sensação boa. Isso pra mim é música. Música traz isso (SONATINA, 2018).

Porque é isso, música e arte é sentir, é pele, e assim por mais que você não tenha, ela te toca de alguma forma. Eu não tenho os dizeres teóricos ou científicos, mas eu acho que é isso, ela desperta as emoções, a gente escuta, lembra e recorda (MELODIA, 2018).

Percebemos que as participantes declararam não ter domínio, bases teóricas, afinação ou aptidão musical. Contudo, todas afirmaram ter a música no contexto de suas vidas, tecendo relatos plasmados de sentido. A música pode ser configurada como algo transcendental, que eleva o Ser às mais intrínsecas sensações. Para Merleau-Ponty (2004, p.15):

Um corpo humano está aí quando, entre vidente e visível, entre tocante e tocado, entre um olho e o outro, entre a mão e a mão se produz uma espécie de recruzamento, quando se acende a faísca do senciente-sensível, quando se inflama o que não cessará de queimar, até que um acidente do corpo desfaça o que nenhum acidente teria bastado para fazer (MERLEAU-PONTY, 2004, p. 15).

Consideramos a música como algo que está preso no tecido corpóreo, misturando sujeito e mundo trazendo uma definição plena do Ser com seu corpo próprio. A linguagem musical envolve a espacialidade e o estar no mundo. O tempo vivido e a música percebida diferem nas itinerâncias dos relatos. Tal processo é explicado pelas nuances que envolvem a percepção da linguagem musical.

Segundo França (2015), uma das maiores especificidades da música é a força que ela tem em trazer a percepção do tempo vivido. Assim, a autora acrescenta "ela nos permite experimentar a relatividade do tempo. Expansão e retração, tensão e dissolução, hesitação e assertividade, pressa e resignação estruturam o tempo na forma, nos motivos e nos gestos, nas surpresas e nas reiterações, conexões tecidas pela memória" (FRANÇA, 2015, p. 52). Nesse contexto, Sonata externou no seu relato aspectos relevantes de sua compreensão sobre a música por meio de experiências. Suas escolhas musicais seguem critérios definidos e ela utiliza cânticos sagrados para momentos de reflexão, estudo e meditação. 
$\mathrm{Na}$ minha vida, em casa eu escuto geralmente música para meditação. Eu uso muito cânticos sagrados e, eu não sei explicar como, mas eu consigo me compreender, eu consigo sentir o que eles estão falando com esses cânticos sagrados, eu consigo sentir o que eles estão tentando passar. É um pouco difícil descrever o sentimento. Eu não consigo explicar o que é música, mas eu sei que ela interfere em diferentes momentos de minha vida (SONATA, 2018).

Percebemos que a música se faz presente na vida das participantes e cada uma pode externar suas impressões por meio do vínculo adquirido e construído. Sonata revelou um sentido diferenciado, denotando uma singularidade ao contato musical oportunizando sensações e interpretações por meio da música. O sentido da música para a participante é algo tão forte e intrínseco que foi possível descrever por meio de configurações subjetivas, porém impossível tecer definições concretas. Ela relatou uma vivência bem particular e profunda. Assim destacamos:

Um desses cânticos sagrados tem uma música sobre a lua, quando a lua está muito cheia, eu gosto de colocar essa música, eu gosto de sentir. Eu consigo sentir a energia da lua junto com a música, dentro do meu quarto. Quando estou sentindo algum medo e preciso me preparar para alguma coisa, escuto uma música que fala sobre a Deusa Mãe, eu gosto de cantar essa música e me sinto mais forte (SONATA, 2018).

O relato mostra-se carregado de configurações subjetivas com relação aos efeitos da música na vida de Sonata. Tal narrativa desvela o nível de intensidade e encadeamento com o fenômeno musical, trazendo para a entrevistada conforto, segurança e comportamentos simbólico-emocionais. De acordo com Copland (1974) para entendermos o que é música devemos vivenciá-la ao ouvir ou sentir com maior intensidade no cotidiano. Dessa forma, somos capazes de fazer relações com algo já vivido ou que ainda estamos por viver. Podemos dizer que se reconhecemos uma música somente pelo ouvir, já temos um início para a apreciação musical. Recorremos mais uma vez às palavras de Rey (2011), buscando aproximar seu pensamento à experiência musical da entrevistada:

A experiência humana desenvolve-se dentro de sistemas de atividades e comunicação simultâneos, e se expressa nas pessoas que compartilham essas atividades através de efeitos colaterais que ocorrem como produções da pessoa através das configurações 
subjetivas que emergem do processo de viver essas experiências (REY, 2011, p. 33).

Consideramos que os efeitos da música para Sonata estabelecem comunicações simultâneas entre as atividades e o fenômeno sonoro. Por outro lado, tal conjuntura de proximidade e conexão com a música é interpretada por Sacks (2007) como um ato de musicofilia adquirido desde a primeira infância, denotando a grande relevância da música na vida humana e causando a impressão de que é quase um ser vivo. Conforme as palavras do autor:

A inclinação para a música revela-se na primeira infância, é manifesta e essencial em todas as culturas e provavelmente remonta aos primórdios da nossa espécie. Essa "musicofilia" é um dado da natureza humana. Ela pode ser desenvolvida ou moldada pela cultura em que vivemos, pelas circunstâncias da vida e pelos talentos ou deficiências que temos como indivíduos. Mas é tão arraigada na natureza humana que devemos considerá-la inata (SACKS, 2007, p. 7).

Maffioletti (2001) trata da musicalidade humana como um dispositivo que está relacionado ao que compreendemos como música, e complementa que é algo que todos nós podemos ter. Hoje a humanidade vivencia a linguagem musical de inúmeras maneiras, inerente de preocupações com aptidão, talento ou competência. Todos os sujeitos trazem a sua musicalidade humana. Merleau-Ponty realça aspectos sobre a percepção da música e diz:

Evidentemente, fica impossível aqui imaginar que a arte remeta a outra coisa que não a si mesma. A música em torno de um tema que nos descreve uma tempestade, ou mesmo uma tristeza, constitui uma exceção. Aqui, estamos incontestavelmente diante de uma arte que não fala. E, contudo, uma música está longe de ser apenas um agregado de sensações sonoras: através dos sons, vemos aparecer uma frase e, de frase em frase, um conjunto e, por fim, um mundo (MERLEAU-PONTY, 2004, p. 62)

Percebemos a grandeza de sensações envolvidas no contato musical, revelando que abrange uma compreensão maior do que a recorrente pelo senso comum. O autor declara que é uma "arte que não fala", no entanto pode trazer uma soma de sentimentos que, se traduzidos em palavras, textos, poemas, melodias, 
revelam o mundo. A música traduz emoções dos sujeitos no mundo de forma subjetiva. Rey (2011) aborda o modo de vida das pessoas partindo do indicador das configurações subjetivas em constante desenvolvimento, ocupando dimensões diferentes de acordo com o comportamento diverso de cada pessoa. Nessa linha, Dallabrida (2015, p.18) declara que "sentidos sugerem a necessidade de conhecer o contexto a aproximar-se de alguns traços de subjetividade de quem lhe atribui, o que implica em ir além do significado estável".

Na mesma linha, as narrativas de Melodia e Sonatina também se mostraram plasmadas de emoções. As falas denotam a presença da música no contexto pessoal de forma a promover estados de humor, comportamento e afetos, enxergando-a sob uma ótica macro e fazem considerações da amplitude da linguagem musical.

Se você pega uma música qualquer, se você para, você consegue perceber a essência da música, ela te diz alguma coisa, mesmo que as vezes você não queira falar, mas de alguma forma pra você ela vai dizer (MELODIA, 2018).

A música nos remete a muitas situações. Eu acho que a música realmente faz parte da nossa memória, das emoções. E ela, não sei como, desperta você ter tal gosto por tal música, como funciona na mente. Mas eu acho que a música serve mesmo como memória (SONATINA, 2018).

Mais uma vez reforçamos a beleza da música ao envolver o Ser em sua totalidade. O mundo desvelado retrata a percepção musical em sua essência, vivenciar a música por inteiro, observando os contornos, as formas, os tons. Tal processo é interpretado de forma tão íntima que a música "fala" ao ser de quem está inebriado nesse movimento de sons e melodias. Pensamos que nem todos os seres humanos tratam a música com tal deleite, ou seja, totalmente imersos em ouvir o que o som tem a dizer.

Merleau-Ponty (1999) tece seu pensamento acerca da capacidade dos seres humanos no que se refere à habilidade de expressão, promovendo leituras e interpretações acerca do que é exposto. O autor destaca que a música possui uma 
singular potência de expressão, permitindo extrairmos o que for possível. Assim, complementa:

A operação de expressão, quando é bem-sucedida, não deixa apenas um sumário para o leitor ou para o próprio escritor, ela faz a significação existir como uma coisa no próprio coração do texto, ela a faz viver em um organismo de palavras, ela a instala no escritor ou no leitor como um novo órgão dos sentidos, abre para nossa experiência um novo campo ou uma nova dimensão. Essa potência da expressão é bem conhecida na arte e, por exemplo, na música. A significação musical da sonata é inseparável dos sons que a conduzem: antes que a tenhamos ouvido, nenhuma análise permitenos adivinhá-la; uma vez terminada a execução, só poderemos, em nossas análises intelectuais da música, reportar-nos ao momento da experiência; durante a execução, os sons não são apenas os "signos" da sonata, mas ela está ali através deles, ela irrompe neles (MERLEAU-PONTY, 1999, p. 248).

Interpretando a potência da expressão na vida dos sujeitos, consideramos que é algo traduzido no seu íntimo, despertando novas experiências e novos significados. A música realça esse movimento, ao oportunizar vivências por meio de sons traduzidos em sonatas, prelúdios, valsas, ou qualquer ritmo escolhido pelo ouvinte. Para Levitin (2010), a música é uma ciência que, ao longo dos anos, revelou-se como uma aventura nunca experienciada duas vezes da mesma forma. É dinâmica e apresenta mudanças no decorrer do tempo conforme a métrica e o ritmo. Reconhecemos que podemos ouvir e apreciar a mesma música, e nesse ínterim, múltiplas e distintas sensações germinam dessa melodia repetida. Podemos ir mais adiante, constatando que, no contato com a música, os seres humanos são afetados de alguma forma, fazendo emergir impressões, reações e significados relativos a ela, seja qual for o estilo ou cadência.

As emoções e sensações permearam de modo frequente as narrativas das entrevistadas, promovendo um caminho fenomenológico de ir e vir. O fenômeno musical se mostra por causa da unidade perceptiva que promove um movimento ao se desfazer e se refazer constantemente (MERLEAU-PONTY, 1999). Podemos considerar o sentido da música como um dispositivo sempre ligado à vida e às relações interpessoais das pedagogas. Nesse sentido, o referido autor compreende que: 
$\mathrm{Na}$ percepção efetiva e tomada no estado nascente, antes de toda fala, o signo sensível e sua significação não são separáveis nem mesmo idealmente. Um objeto é um organismo de cores, de odores, de sons, de aparências táteis que se simbolizam e se modificam uns aos outros e concordam uns com os outros segundo uma lógica real que a ciência tem por função explicitar, e da qual ela está muito longe de ter acabado a análise (MERLEAU-PONTY, 1999, p. 68).

Compreendemos a música como esse signo sensível que não separa corpo e mundo, cujo teor lógico a ciência busca explicar. Mesmo não sendo o cerne desse trabalho, cabe realçar os estudos e pesquisas em volta do fenômeno musical como dispositivo importante para a ativação do sistema neural. O campo tem se expandido resultando em descobertas científicas comprovando os benefícios da música no cérebro. Podemos mencionar autores como Sacks (2007), Levitin (2010), dentre outros. Nessa linha, ao narrar sobre o sentido da música a participante Melodia externou aspectos relevantes, ao demonstrar uma compreensão alargada frente ao fenômeno musical. Seu relato é rico de expressões subjetivas. Em contrapartida, Sonata também deposita grandes percepções ao fenômeno sonoro desvelando a impossibilidade de tecer definições. Assim descreveram:

A música é arte, ela é sentida, a gente não aprende a fazer arte, a gente não aprende a enxergar arte, a gente aprende a sentir, arte é pele. A palavra é essa pra música, pra qualquer outro seguimento ela é o sentir, então isso está totalmente ligado às emoções (MELODIA, 2018).

Quando eu quero me concentrar um pouquinho, eu estou muito estressada. Quando eu vejo que, sei lá, uma pessoa olhar pra mim pode me desestabilizar e eu sei que eu não sou isso, eu gosto de colocar uma música mais calma, sentar me concentrar, tentar voltar pra quem eu realmente sou. A música me ajuda nesse aspecto. Fim de semana quando você quer sair, você quer ir pra uma festa, eu gosto de escutar uma música eletrônica, por exemplo, em alguma festa, alguma coisa. (SONATA, 2018).

A música estabelece uma interligação tão intensa conforme a percepção de Sonata, que é possível retomar estados de consciência e comportamento. Ela descreve a diferença de estilos musicais conforme o contexto, o sentimento e os momentos vivenciados. Na mesma direção, percebemos a profundidade do sentido da música para Melodia. Consideramos que o seu olhar está além de preposições 
objetivas, invade o que é subjetivo tornando latente a relação entre corpo e fenômeno. O relato da entrevistada realça que arte não se aprende, o campo envolve sentimento, corpo e pensamento.

Cabe realçar que, quando envidamos esforços para o ensino de música, não estamos pensando incisivamente em incutir nos estudantes a linguagem musical. $O$ processo inicial se dá pela sensibilização, esse é o ponto crucial para a percepção da música. Primeiramente, pensamos em mostrar a beleza da música, desenvolver a audição, reconhecer a singularidade dos sons ao nosso redor. Portanto, nosso pensamento estabelece aproximação com a fala de Melodia, ao dizer que a "arte não se aprende", ou seja, faz-se necessário levar o sujeito a sentir, podendo, posteriormente, direcionar suas escolhas. Nesse sentido, consideramos pertinentes as palavras de Giorgi (2014) adequando-as ao objeto musical no que tange à sua relação com a consciência:

Um fenômeno, no contexto fenomenológico, significa sempre que o que é dado ou se apresenta dele próprio não se compreende senão em sua relação com a consciência. A intencionalidade significa que a consciência sempre se dirige a um objeto que a transcende. A fenomenologia se interessa pelos fenômenos que se oferecem ao indivíduo, porque nada é possível sem levar em consideração a consciência; porém todo dado deve ser compreendido como fenômeno e não como existente real (GIORGI, 2014, p.390).

Mencionamos a importância da intencionalidade ao vivenciar música. Compreendemos que tal arte não pode ser oferecida de qualquer forma, sem levar em consideração as pessoas, o espaço e a realidade de cada contexto. O olhar intencional para o sentido da música traz desvelamentos do fenômeno de forma peculiar, conforme as narrativas de cada pedagoga. Por maior que seja a intimidade e vínculo com a linguagem musical, essa sempre ocupará um lugar subjetivo indicador da relação intrínseca com a consciência.

Segundo Bicudo (1994, p.21), a essência fenomenológica não é totalmente abstrata ou distanciada da práxis, mas ela se revela no movimento próprio do fazer reflexivo: "ao desvendar a essência, a consciência, em um movimento reflexivo, realiza a experiência de percebê-la, abarcando-a compreensivamente, ou seja, trazendo-a para o seu círculo de inclusão ou horizonte de compreensão". 
Além de todas as vertentes oportunizadas pela música interpretadas até o momento, consideramos a conexão da música com o corpo. As narrativas desvelaram dispositivos importantes acerca do vínculo musical e corpóreo entre os sujeitos. Merleau-Ponty (1999) declara o corpo como objeto e ponto de vista do mundo e das relações com o mudo objetivo. Nessa linha acrescenta:

Trato minha própria história perceptiva como um resultado de minhas relações com o mundo objetivo; meu presente, que é meu ponto de vista sobre o tempo, torna-se um momento do tempo entre todos os outros, minha duração um reflexo ou um aspecto abstrato do tempo universal, assim como meu corpo um modo do espaço objetivo (MERLEAU-PONTY, 1999, p. 108).

Ao conceber sua vivência no mundo, os sujeitos são envolvidos em processos diversos e complexos. A história mostra um Ser que é objetivo e subjetivo ao mesmo tempo, envolve corpo e emoção, traçando momentos individuais e coletivos. Como trata Merleau-Ponty, nosso corpo traduz nosso espaço, nossa participação no mundo objetivo, definindo reflexos de recepção, satisfação, rejeição ou angústia. Assim, retomando a narrativa de Sonata, ela declarou que ao vivenciar uma experiência com música e movimentos corporais, percebeu sua coordenação rítmica totalmente desarticulada. Assim, eis o relato:

Eu conheci a escola Waldorf, em Dendê da Serra. Eles faziam rodas usavam chocalhos, usavam cânticos e usavam cantigas. Eu percebi que eu não tenho ritmo nenhum! Enquanto as crianças estavam indo pra frente, meio que eu ia pra trás. Tinha a questão de abrir uma roda, fechar, abrir um braço, bater palmas, seguir um ritmo e é muito simples. Mas quando eu fui fazer eu não consegui. Senti que não tenho domínio do meu corpo e que ele poderia estar mais harmônico (SONATA, 2018).

O relato de Sonata é tomado pela frustração ao sentir-se incapaz de participar da atividade em harmonia com os outros sujeitos, ou seja, o reflexo do abstrato revelou o tempo do seu corpo no mundo. A fenomenologia permite o olhar interpretativo sob o conhecimento da angústia da entrevistada. Critelli (2006) retrata que a base fenomenológica possibilita mostrar o homem, bem como as formas infindas de ser, promovendo o movimento de relatividade. Nesse contexto, esta autora esclarece que a relatividade é vista "como uma condição que os entes tem de 
se manifestarem no horizonte do tempo e não do intelecto, e em seu incessante movimento de mostrar-se e ocultar-se" (CRITELLI, 2006, p. 15).

\section{CONSIDERAÇÕES FINAIS}

Neste artigo apresentamos os resultados de uma pesquisa fenomenológica sobre os sentidos de música presentes nas narrativas de pedagogas-professoras em atividade de docência nos anos iniciais do ensino fundamental no município de Vitória da Conquista-Bahia.

Ao discorrer sobre as múltiplas vertentes que abarcam o fenômeno musical, podemos considerar aspectos envolvendo a ressignificação de valores dos seres humanos. Consideramos que o olhar sensível e o envolvimento referente à música, promovem caminhos relevantes no modo de ser, viver, e neste estudo, de ensinar, de educar e de desenvolver as práticas pedagógicas na sala de aula.

O percurso permeado pelas interpretações das narrativas nos permitiu desvelar singularidades do fenômeno musical. As falas revelam o mundo percebido e trouxeram descobertas nas diferentes formas de escutar, perceber e sentir a música. Por meio de cânticos sagrados, para acalmar, ou por mero prazer de ouvir, a música atravessou a vida das pedagogas.

\section{REFERÊNCIAS}

BELLOCHIO, Cláudia. Educação Básica, professores unidocentes e música: pensamentos em tríade. In: BELLOCHIO, Cláudia Ribeiro. GARBOSA, Luciane W. Freitas. (org.). Educação musical e pedagogia: pesquisas, escutas e ações. 1. Ed. Campinas, SP: Mercado das Letras, 2014.

BELLOCHIO, Cláudia Ribeiro. GARBOSA, Luciane W. Freitas. (org.). Educação musical e pedagogia: pesquisas, escutas e ações. 1. Ed. Campinas, SP: Mercado das Letras, 2014.

BELLOCHIO, Cláudia. WEBER, Vanessa. SOUZA, Zelmielen. Música e unidocência: pensando a formação e as práticas de professores de referência. Revista da FAEEBA Educação e Contemporaneidade. Salvador, V. 26, nº 48, p. 205-221, jan./abr. 2017.

BEYER, Esther. KEBACH, Patrícia. (Org.). Pedagogia da música; experiências de apreciação musical: Porto Alegre: Editora Mediação, 2016.

BICUDO, Maria Aparecida V. Sobre a Fenomenologia. In ESPOSITO, Vitória

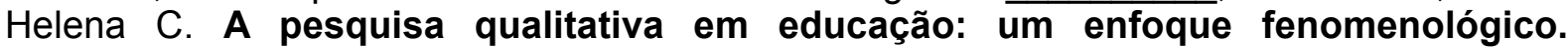


Sociedade de Estudos e Pesquisa Qualitativa. II Congresso Estadual Paulista sobre formação de educadores. Piracicaba: Editora Unimep, 1994.

BRASIL. Lei No 11.769/2008. Altera a Lei no 9.394, de 20 de dezembro de 1996, Lei de Diretrizes e Bases da Educação, para dispor sobre a obrigatoriedade do ensino da música na educação básica. Diário Oficial, Brasília, 2008.

BREIN, Ricardo. O músico educador e o educador músico. In: JORDÃO, Gisele;

ALLUCCI, Renata. et al. A música na escola. Ministério da Cultura e Vale. Allucci \& Associados Comunicações. São Paulo, 2012.

BRITO, Teca de Alencar. Koellreutter educador: o humano como objetivo da educação musical. 2. ed. São Paulo: Peirópolis, 2011.

CRITELLI, Dulce. A condição humana como valor e princípio para a educação. Cadernos Cenpec. $N^{\circ} 2,2006$

DALLABRIDA, lara Cadore. Educação musical e unidocência: um estudo com professoras dos anos iniciais do Ensino Fundamental. Trabalho de Conclusão de Curso (Música - Licenciatura Plena), Universidade Federal de Santa Maria. Santa Maria, 2013.

Sentidos da educação musical na formação acadêmico-profissional do pedagogo. 150f. Dissertação (Mestrado em Educação). Faculdade de Educação, Universidade Federal de Santa Maria, Santa Maria, 2015.

FERREIRA, Marcos de Souza. Ensino de música no Instituto Federal da Bahia: paradigmas e paradoxos. 229f.Tese (Doutorado em Música). Escola de Música, Universidade Federal da Bahia, Salvador, 2017.

FISCHER, Ernst. A necessidade da arte. 9. ed. Rio de Janeiro: LTC, 1987.

FONTERRADA, Marisa T. de Oliveira. Linguagem verbal e linguagem musical. Cadernos de Estudo: Educação Musical, n. 4 e 5. São Paulo, 1994.

FRANÇA, Cecília Cavaliere. A interdisciplinaridade da vida e a multidimensionalidade da música. Música na educação básica. Vol. 7, n. 7/8. Londrina: Associação Brasileira de Educação Musical, ABEM, 2016.

GIORGI, Amedeo. Sobre o método fenomenológico utilizado como modo de pesquisa qualitativa nas ciências humanas: teoria, prática e avaliação. In: POUPART, Jean; DESLAURIERS, Jean-Pierre; GROULX, Lionel-H. A pesquisa qualitativa: enfoques epistemológico e metodológico. Trad. Ana Cristina Nasser. $2^{\mathrm{a}}$ Ed. Petrópolis, RJ: Vozes, 2014.

HENTSCHKE, Liane. A Educação Musical: um desafio para a Educação. Educação em Revista, n.38, p.55-61, 2003.

LEVITIN, Daniel J. A Música no seu cérebro: a ciência de uma obsessão humana. Rio de Janeiro: Civilização Brasileira, 2010.

MAFFIOLETTI, Leda de A. Musicalidade humana: Aquela que todos podem ter. In: Anais do IV Encontro Regional da ABEM Sul, I Encontro do Laboratório de Ensino de Música/LEMCE-UFSM. Educação Musical hoje: Múltiplos Espaços. Novas demandas profissionais. UFSM/RS, 23 a 25 de maio de 2001. 
MERLEAU-PONTY, Maurice. Fenomenologia da percepção. (tradução Carlos Alberto Ribeiro de Moura). 2. ed. São Paulo: Martins Fontes, 1999.

Conversas. Stéphanie Ménasé (Ed.). Fábio Landa (Trad.). São Paulo:

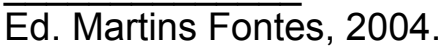

MONTEIRO, Maurício. Resenha. SACKS, Oliver. Alucinações Musicais: relatos sobre a música e o cérebro. Revista de História 157 - Dossiê História e Música. Universidade de São Paulo: São Paulo, 2007.

PENNA, Maura. Música (s) e seu ensino. 2. ed. Porto Alegre: Sulina, 2014.

REY, Fernando L. G. Pesquisa qualitativa em Psicologia: caminhos e desafios. São Paulo: Thomson, 2002.

2011.

Subjetividade e saúde: superando a clínica da patologia. São Paulo: Cortez,

SACKS, Oliver. Alucinações Musicais: relatos sobre a música e o cérebro. São Paulo: Cia. das Letras, Tradução de Laura Teixeira Motta. 2007.

SNYDERS, Georges. A escola pode ensinar as alegrias da música? 5. ed. São Paulo: Cortez, 2008. 